\title{
Smiley guests post long reviews!
}

\author{
Chunhong Li ${ }^{\text {a }}$, Qiang Ye ${ }^{\text {a }}$, Juan Luis Nicolau ${ }^{\text {b }}$, Xianwei Liu ${ }^{\text {a, }}$ \\ ${ }^{a}$ School of Management \\ Harbin Institute of Technology \\ 92 West Dazhi Street, Harbin, China \\ E-mail: lichunhong2010@163.com \\ E-mail: yeqiang@hit.edu.cn \\ *E-mail: liuxianwei@126.com \\ ${ }^{\mathrm{b}}$ Howard Feiertag Department of Hospitality and Tourism Management \\ Pamplin College of Business \\ Virginia Tech \\ Blacksburg, VA 24061, USA \\ E-mail: jnicolau@vt.edu
}

\section{Citation:}

Li, C., Ye, Q., Nicolau, JL and Liu, X. (2021). Smiley guests post long reviews!, International Journal of Hospitality Management, 96, 102963,

Acknowledgement: This research is partially supported by NSFC (71701100). 


\title{
Smiley guests post long reviews!
}

\begin{abstract}
The inclusion of a photo in users' profile provides information about them and shows a higher sense of self-expression and potential engagement. On peer-to-peer rental platforms, profile images may be useful for hosts and guests to infer individual characteristics and expectations. We try to fill a gap in the literature by inferring guests' posting behavior through their profile image. Using Airbnb data and deep learning techniques, our empirical analysis reveals that guests who upload profile images - especially profile images displaying happy emotions - are more involved in posting long reviews. As theoretical implications, these results add knowledge to the application of the Five Factor Model of Personality, deep learning, image recognition, and emotion recognition in hospitality. As managerial implications, the prediction of posting behavior through the mining of visual information can be a relevant tool in the age of big data.
\end{abstract}

Keywords: Airbnb; reviews; profile image; deep learning; personality. 


\section{Introduction}

On peer-to-peer rental platforms, trust is a critical factor (Agag and Eid, 2019; Belarmino and Koh, 2020; Ye et al., 2019), hence a host's profile image becomes an important information source for potential guests to infer the characteristics of a host and thus exerts certain effects on their booking decisions. For example, leveraging an experiment, Ert et al. (2016) found that if potential guests perceive a host as being more trustworthy based on the host's profile image, they are more likely to rent the host's properties. Ert and Fleischer (2020) further showed that smiley hosts (profile image) are perceived as more attractive and trustworthy. These studies indicated that the way potential guests perceive the host's profile image will affect their decision making. Likewise, the profile on guests is also relevant to enhance the trust between hosts and guests.

Inspired by these studies, we propose a novel research question: should we infer guests' posting behavior through their profile image? By answering this question, we try to fill a gap in the literature. Note that research has shown that users who provide their profile name are more involved in posting long reviews as the profile name is a fundamental attribute of sense of belonging in an online community (Liu et al., 2019). Compared with the textual name, profile image should contain more information about a user and convey a higher level of social presence in the online environment (Karimi and Wang, 2017). Based on the Five Factor Model of Personality (extraversion, agreeableness, conscientiousness, neuroticism, and openness; Digman, 1990) which has been widely employed for the analysis of social media users (Eftekhar et al., 2014), Kim and Kim (2018) stated that "Photos are playing a great role in self-expression online" and found that Instagram users with higher level of extraversion posted more photos with human faces and happier emotions; likewise, using Twitter profile images, Liu et al. (2016) found that extraverts tend to display positive emotions. Therefore, it is expected that users who upload and select a profile image may have a higher sense of self-expression; users who provide profile image with happy emotions are expected to be active or outgoing (Kim and Kim, 2018; Liu et al., 2016). As review length 
indicates a poster's willingness to contribute or express (Filieri et al., 2019), this study aims to explore - for the first time-whether guests who provide profile image (with human) are more involved in expressing and thus post long reviews. By the same token, and considering, even if anecdotally, that the face is the mirror of the soul, we further examine whether guests who provide profile image displaying happy emotions are more involved in posting long reviews.

Contributing online can be time-consuming and costly. Thus, user reviews are usually short and brief, limiting their value to the platform (Burtch et al. 2018, Mudambi and Schuff 2010). Long reviews are beneficial to the development of UGC websites which depend heavily on user generated content to attract new users and maintain current ones. Moreover, extensive studies have shown that the length of a review is positively associated with its usefulness/helpfulness (Mudambi and Schuff, 2010). Therefore, the findings of this study offer practical implications for peer-to-peer rental platforms to encourage and enhance online contributions..

\section{Data and methodology}

\subsection{Data collection}

We collect guest reviews from Airbnb, the most popular and iconic home-sharing platform. First, we develop a Python-based crawler to retrieve all the properties listed on Airbnb in Beijing (the capital city of China), the tourism revenue (622.46 billion RMB in 2019 with 322 million tourists) of which ranked \#1 among all the cities in China according to the Ministry of Culture and Tourism of China. Second, we download information from all the reviews of these properties and their posters - that is, the posting date, the rating score, and the length of each review; the profile image of the guest, whether the guest is verified or a superhost, how many items the guest provided to Airbnb, and the registration date of the guest. Third, to ensure the quality of our dataset, we only keep the reviews posted in Chinese and in 2019 because some guests would change their profile image after a certain period. 
Finally, we only keep the latest review of each guest to avoid repeated reviews from the same guest. As a result, 98,323 guest reviews remain in our final dataset. Data collection is conducted in January 2020.

\subsection{Pattern recognition}

Two deep learning algorithms are employed to perform human recognition and emotion recognition of the profile image. First, YOLOv3, trained with the Microsoft COCO dataset, is used to detect whether there is human in the profile image (Redmon and Farhadi, 2018). The accuracy of human recognition is $96.42 \%$. Second, Xception, trained with the FER-2013 dataset, is adopted to recognize the specific emotion of the human face in the profile image (Chollet, 2017). This algorithm classifies the emotion of a specific profile image with a human face into seven categories: happy, neutral, sad, angry, surprised, fearful, and disgusted. The accuracy of emotion recognition is $92.38 \%$ (happy), $86.19 \%$ (neutral), $84.31 \%$ (sad), 94.42\% (surprised), 88.79\% (angry), 98.80\% (disgusted), and 86.10\% (fearful). Figure 1 presents an example of the outcome of these two algorithms (for privacy reasons, the images in Figure 1 are from public figures). For brevity, the technical details are not listed.

Figure_1_here

\subsection{Variables}

To explore whether the profile image predicts guests' posting behavior, we employ the following three explanatory variables. First, WithPhoto, a dummy variable to denote whether a guest uploaded a photo to his/her profile $(1=\mathrm{yes}, 0=$ no). Second, WithHuman, a dummy variable to denote whether a guest used a photo with human as his/her profile image. Third, Emotion (Happy, Neutral, Sad, Angry, Surprised, Fearful, and Disgusted), a categorical variable to indicate the emotion of the profile image. We also employ fixed effects (property and month) and several covariates to control for heterogeneity across properties, time, and guests. The covariates include the rating score (ranging from 1 to 5), whether the guest is verified $(1=$ yes, $0=$ no $)$ or a superhost $(1=$ yes, $0=$ no), number of items (e.g., ID card and email) the guest provided to Airbnb, and the registration date. 


\section{Results}

\subsection{Main results}

The average length of the 98,323 reviews is about 60.9 words. Among these profile images, 89,976 are detected with human and 26,124 pass the emotion recognition algorithm: happy $(30.2 \%)$, neutral $(49.1 \%)$, sad $(10.0 \%)$, angry (3.6\%), surprised $(3.1 \%)$, fearful $(3.8 \%)$, and disgusted $(0.2 \%)$. As observed in column 1 of Table 1 , the coefficient $(2.698 * * *)$ of WithPhoto is positive and significant, indicating that guests with a profile image tend to post longer reviews in comparison with guests without a profile image. We then explore whether guests with human in their profile image are more likely to express and report the empirical results in column 2 . The positive and significant coefficient $\left(1.050^{* *}\right)$ suggests that guests using photos with human as their profile image tend to write longer reviews. These results support our conjecture that guests with profile images have a high sense of self-expression and thus tend to post long reviews.

Table_1_here

To examine whether the emotions embedded in the profile image can indicate guests' posting behavior, we recognize the emotion of guests' profile image through deep learning and conduct empirical analysis combined with the reviews posted by them. As observed in Table 2, only the coefficient (6.221***) of Happy is positive and significant; the coefficients of the other emotions are either negative or insignificant. This result indicates that guests who use profile image displaying happy emotions are more involved in expressing and thus post long reviews. In particular, reviews posted by those who use profile images displaying happy emotions are about $10 \%(6.221 / 60.9)$ longer.

Table_2_here 


\subsection{Robustness analysis}

It is possible that some guests may change their profile image after a certain period. To address this concern, we restrict the research samples to the reviews posted half a year before the date of data collection. We then replicate the results in Table 2 and report these results in Table 3. As observed in Table 3, the coefficients of interest remain positive and significant, suggesting that the results are robust even after we restrict the samples.

Table_3_here

To check the accuracy of the two algorithms in the context of Airbnb, we randomly select 1,000 images and employ four research assistants (plus two authors of this paper) to label them independently. In the situation of $>=4$ participants reach a consensus on labeling each profile image regarding Human and Happy, the accuracy of algorithm output is about $93.5 \%$ for Human detection and $82.6 \%$ for Happy recognition. Therefore, fine-tuning these two models with the real dataset would be valuable and deserve future research effort.

\section{Conclusion}

Using data collected from Airbnb and deep learning techniques, our empirical analysis reveals that guests who upload profile image (with human) — especially those who use profile image displaying happy emotions - are more involved in posting long reviews. This study is among the first attempts to infer guests' posting behavior through their profile image, extending the application of the Five Factor Model of Personality, deep learning, and image recognition in hospitality. Predicting buyers' or sellers' posting behavior through the mining of visual information should be a potential research direction in the age of big data.

User-generated content (UGC) has become a powerful economic phenomenon. Although UGC cannot be directly transformed into revenue streams, it is a strong driver behind online users' website loyalty (Goes et al. 2016). Indeed, UGC is key to the success of many leading Web 2.0 companies (e.g., TripAdvisor and Amazon); in some cases, a website's success is 
derived entirely from UGC (e.g., Wikipedia). However, user reviews are usually short as contributing online is costly. Long reviews are more beneficial for websites that are heavily reliant on UGC, such as peer to peer accommodation platforms, online travel agencies, and travel review websites. As our findings indicate, guests with profile image - especially those using happy image - are more involved in posting long reviews. Thus, we suggest that these platforms pay more attention to this group when designing incentives to encourage user activities. They can also employ deep learning techniques to detect the emotion pattern of their users' profile image. A customized incentive system would perform better than a uniform one in encouraging users to contribute, given that deploying monetary (e.g., reward points) or nonmonetary (e.g., badge ranks) incentives to encourage user contributions has become a common business practice.

\section{References}

Agag, G., \& Eid, R. (2019). Examining the antecedents and consequences of trust in the context of peer-to-peer accommodation. International Journal of Hospitality Management, 81, 180-192.

Belarmino, A., \& Koh, Y. (2020). A critical review of research regarding peer-to-peer accommodations. International Journal of Hospitality Management, 84, 102315.

Burtch, G., Hong, Y., Bapna, R., \& Griskevicius, V. (2018). Stimulating online reviews by combining financial incentives and social norms. Management Science, 64(5), 2065-2082.

Chollet, F. (2017). Xception: Deep learning with depthwise separable convolutions. Proceedings of the IEEE conference on computer vision and pattern recognition,1251-1258.

Digman, J. M. (1990). Personality structure: Emergence of the five-factor model. Annual Review of Psychology, 41(1), 417-440.

Eftekhar, A., Fullwood, C., \& Morris, N. (2014). Capturing personality from Facebook photos and photo-related activities: How much exposure do you need? Computers in Human Behavior, 37, 162-170.

Ert, E., \& Fleischer, A. (2020). What do Airbnb hosts reveal by posting photographs online 
and how does it affect their perceived trustworthiness? Psychology \& Marketing, 37(5), 630-640.

Ert, E., Fleischer, A., \& Magen, N. (2016). Trust and reputation in the sharing economy: The role of personal photos in Airbnb. Tourism Management, 55, 62-73.

Filieri, R., Raguseo, E., \& Vitari, C. (2019). What moderates the influence of extremely negative ratings? The role of review and reviewer characteristics. International Journal of Hospitality Management, 77, 333-341.

Goes, P. B., Guo, C., \& Lin, M. (2016). Do incentive hierarchies induce user effort? Evidence from an online knowledge exchange. Information Systems Research, 27(3), 497-516.

Karimi, S., \& Wang, F. (2017). Online review helpfulness: Impact of reviewer profile image. Decision Support Systems, 96, 39-48.

Kim, Y., \& Kim, J. H. (2018). Using computer vision techniques on Instagram to link users' personalities and genders to the features of their photos: An exploratory study. Information Processing \& Management, 54(6), 1101-1114.

Liu, L., Preotiuc-Pietro, D., Samani, Z. R., Moghaddam, M. E., \& Ungar, L. (2016). Analyzing personality through social media profile picture choice. In Proceedings of the International AAAI Conference on Web and Social Media, 211-220.

Liu, X., Liu, J., Law, R., \& Liang, S. (2019). Power of profile name in online sharing. International Journal of Hospitality Management, 81, 30-33.

Mudambi, S. M., \& Schuff, D. (2010). What makes a helpful online review? A study of customer reviews on Amazon. com. MIS Quarterly, 34(1), 185-200.

Renuka, M. (2019). To be or not to be a host in the peer-to-peer accommodation sector. International Journal of Hospitality Management, 81, 159-168.

Redmon, J., \& Farhadi, A. (2018). Yolov3: An incremental improvement. arXiv preprint arXiv: 1804.02767.

Ye, S., Ying, T., Zhou, L., \& Wang, T. (2019). Enhancing customer trust in peer-to-peer accommodation: A “soft" strategy via social presence. International Journal of Hospitality Management, 79, 1-10. 


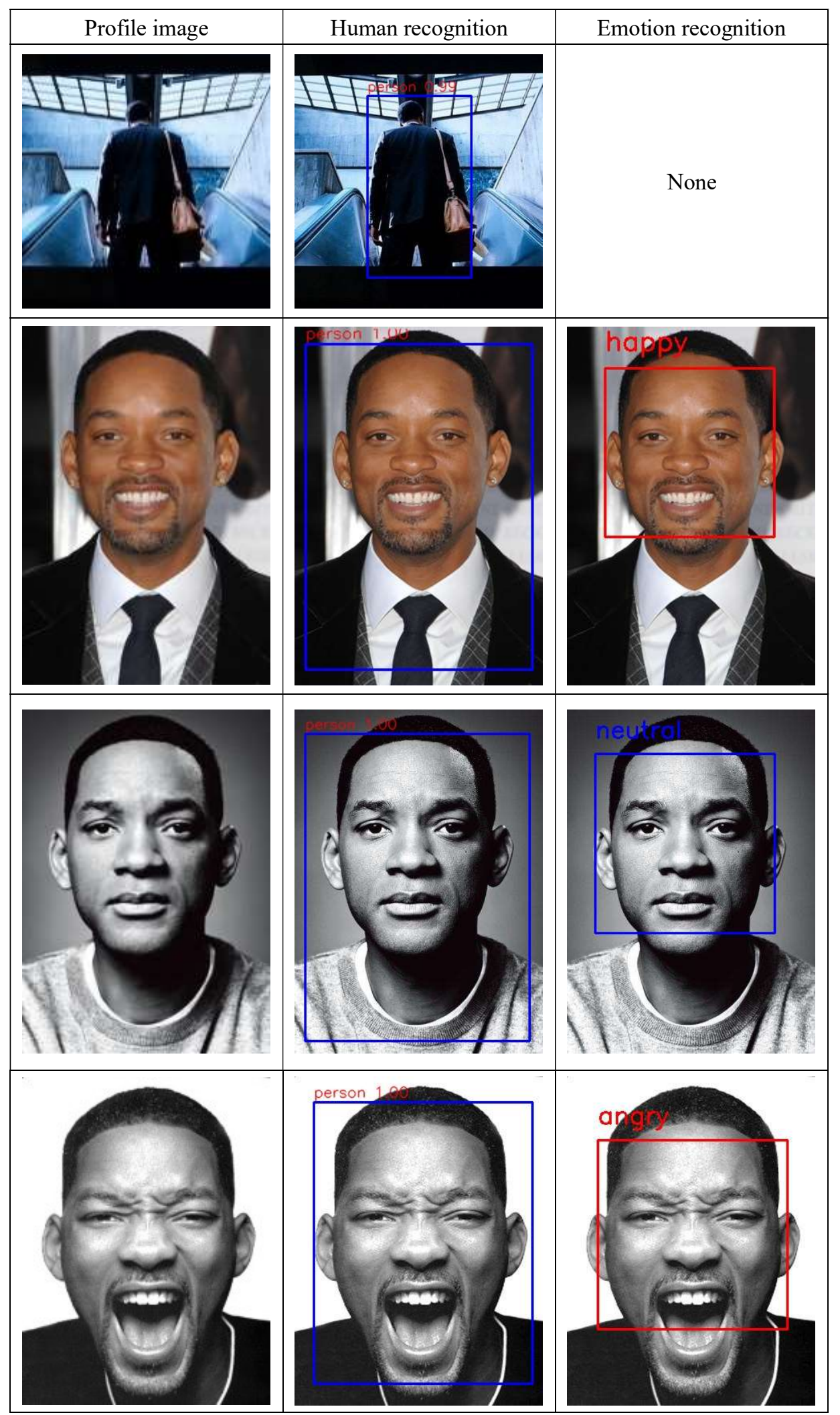

Figure 1. Outcome of pattern recognition. 
Table 1. Profile image and review length.

(1)

(2)

\begin{tabular}{lcc} 
Variables & Length & Length \\
\hline WithPhoto & $2.698^{* * *}$ & \\
WithHuman & $(0.810)$ & \\
& & $1.050^{* *}$ \\
Rating & & $(0.521)$ \\
& $-20.913^{* * *}$ & $-21.110^{* * *}$ \\
SuperHost & $(0.803)$ & $(0.852)$ \\
& $6.880^{* *}$ & $6.671^{* *}$ \\
Verified & $(3.029)$ & $(3.047)$ \\
& $-3.607^{* * *}$ & $-3.776^{* * *}$ \\
Provided & $(0.540)$ & $(0.578)$ \\
& $1.559^{* * *}$ & $1.583^{* * *}$ \\
RegDate & $(0.279)$ & $(0.289)$ \\
& $2.333^{* * *}$ & $2.323^{* * *}$ \\
Constant & $(0.223)$ & $(0.229)$ \\
& $156.265^{* * *}$ & $159.119^{* * *}$ \\
Rouse FE & $(4.194)$ & $(4.410)$ \\
Month FE & YES & YES \\
Obs. & YES & YES \\
\hline & 98,323 & 89,976 \\
& 0.000 & 0.000 \\
& 0.240 & 0.244 \\
\hline
\end{tabular}

Robust standard errors in parentheses

${ }^{* * *} \mathrm{p}<0.01,{ }^{* *} \mathrm{p}<0.05,{ }^{*} \mathrm{p}<0.1$ 
Table 2. Emotion of the profile image and review length.

\begin{tabular}{|c|c|c|c|c|c|c|c|}
\hline Variables & $\begin{array}{c}\text { (1) } \\
\text { Length }\end{array}$ & $\begin{array}{c}\text { (2) } \\
\text { Length }\end{array}$ & $\begin{array}{c}\text { (3) } \\
\text { Length }\end{array}$ & $\begin{array}{c}\text { (4) } \\
\text { Length }\end{array}$ & $\begin{array}{c}\text { (5) } \\
\text { Length }\end{array}$ & $\begin{array}{c}\text { (6) } \\
\text { Length }\end{array}$ & $\begin{array}{c}(7) \\
\text { Length }\end{array}$ \\
\hline Happy & $\begin{array}{c}6.221 * * * \\
(1.245)\end{array}$ & & & & & & \\
\hline Neutral & & $\begin{array}{c}-5.252 * * * \\
(1.091)\end{array}$ & & & & & \\
\hline Sad & & & $\begin{array}{c}1.112 \\
(1.820)\end{array}$ & & & & \\
\hline Angry & & & & $\begin{array}{l}-2.535 \\
(2.972)\end{array}$ & & & \\
\hline Surprised & & & & & $\begin{array}{c}1.770 \\
(3.060)\end{array}$ & & \\
\hline Fearful & & & & & & $\begin{array}{l}-1.311 \\
(2.607)\end{array}$ & \\
\hline Disgusted & & & & & & & $\begin{array}{c}-8.631 \\
(10.008)\end{array}$ \\
\hline Rating & $\begin{array}{c}-21.119 * * * \\
(1.935)\end{array}$ & $\begin{array}{c}-21.179 * * * \\
(1.935)\end{array}$ & $\begin{array}{c}-21.246^{* * *} \\
(1.938)\end{array}$ & $\begin{array}{c}-21.241 * * * \\
(1.938)\end{array}$ & $\begin{array}{c}-21.246^{* * *} \\
(1.938)\end{array}$ & $\begin{array}{c}-21.240 * * * \\
(1.938)\end{array}$ & $\begin{array}{c}-21.244 * * * \\
(1.938)\end{array}$ \\
\hline SuperHost & $\begin{array}{c}7.648 \\
(6.214)\end{array}$ & $\begin{array}{c}7.785 \\
(6.229)\end{array}$ & $\begin{array}{c}7.983 \\
(6.234)\end{array}$ & $\begin{array}{c}7.936 \\
(6.231)\end{array}$ & $\begin{array}{c}7.987 \\
(6.237)\end{array}$ & $\begin{array}{c}7.994 \\
(6.234)\end{array}$ & $\begin{array}{c}7.968 \\
(6.234)\end{array}$ \\
\hline Verified & $\begin{array}{c}-3.863 * * * \\
(1.323)\end{array}$ & $\begin{array}{c}-3.887 * * * \\
(1.324)\end{array}$ & $\begin{array}{c}-3.816^{* * *} \\
(1.325)\end{array}$ & $\begin{array}{c}-3.803 * * * \\
(1.325)\end{array}$ & $\begin{array}{c}-3.806^{* * *} \\
(1.325)\end{array}$ & $\begin{array}{c}-3.809^{* * *} \\
(1.325)\end{array}$ & $\begin{array}{c}-3.813 * * * \\
(1.325)\end{array}$ \\
\hline Provided & $\begin{array}{c}1.698 * * * \\
(0.622)\end{array}$ & $\begin{array}{c}1.750 * * * \\
(0.622)\end{array}$ & $\begin{array}{c}1.682 * * * \\
(0.623)\end{array}$ & $\begin{array}{c}1.671 * * * \\
(0.622)\end{array}$ & $\begin{array}{c}1.673 * * * \\
(0.622)\end{array}$ & $\begin{array}{c}1.669 * * * \\
(0.622)\end{array}$ & $\begin{array}{c}1.677 * * * \\
(0.622)\end{array}$ \\
\hline RegDate & $\begin{array}{c}2.036^{* * *} \\
(0.462)\end{array}$ & $\begin{array}{c}2.058 * * * \\
(0.462)\end{array}$ & $\begin{array}{c}2.239 * * * \\
(0.461)\end{array}$ & $\begin{array}{c}2.245^{* * *} \\
(0.461)\end{array}$ & $\begin{array}{c}2.239 * * * \\
(0.461)\end{array}$ & $\begin{array}{c}2.239 * * * \\
(0.461)\end{array}$ & $\begin{array}{c}2.236^{* * *} \\
(0.461)\end{array}$ \\
\hline Constant & $\begin{array}{c}157.810^{* * *} \\
(10.131)\end{array}$ & $\begin{array}{c}162.331 * * * \\
(10.182)\end{array}$ & $\begin{array}{c}159.888^{* * *} \\
(10.149)\end{array}$ & $\begin{array}{c}160.078^{* * *} \\
(10.158)\end{array}$ & $\begin{array}{c}159.950 * * * \\
(10.162)\end{array}$ & $\begin{array}{c}160.057 * * * \\
(10.155)\end{array}$ & $\begin{array}{c}160.014 * * * \\
(10.157)\end{array}$ \\
\hline House FE & YES & YES & YES & YES & YES & YES & YES \\
\hline Month FE & YES & YES & YES & YES & YES & YES & YES \\
\hline Obs. & 26,124 & 26,124 & 26,124 & 26,124 & 26,124 & 26,124 & 26,124 \\
\hline Prob $>F$ & 0.000 & 0.000 & 0.000 & 0.000 & 0.000 & 0.000 & 0.000 \\
\hline $\mathrm{R}$-squared & 0.403 & 0.403 & 0.402 & 0.402 & 0.402 & 0.402 & 0.402 \\
\hline
\end{tabular}

Robust standard errors in parentheses

$$
{ }^{* * *} \mathrm{p}<0.01,{ }^{* *} \mathrm{p}<0.05,{ }^{*} \mathrm{p}<0.1
$$


Table 3. Emotion of the profile image and review length (robustness check).

\begin{tabular}{|c|c|c|c|c|c|c|c|}
\hline Variables & $\begin{array}{c}(1) \\
\text { Length }\end{array}$ & $\begin{array}{c}(2) \\
\text { Length }\end{array}$ & $\begin{array}{c}(3) \\
\text { Length }\end{array}$ & $\begin{array}{c}\text { (4) } \\
\text { Length }\end{array}$ & $\begin{array}{c}\text { (5) } \\
\text { Length }\end{array}$ & $\begin{array}{c}(6) \\
\text { Length }\end{array}$ & $\begin{array}{c}\text { (7) } \\
\text { Length }\end{array}$ \\
\hline Happy & $\begin{array}{c}5.374 * * * \\
(1.852)\end{array}$ & & & & & & \\
\hline Neutral & & $\begin{array}{c}-4.561 * * * \\
(1.620)\end{array}$ & & & & & \\
\hline $\mathrm{Sad}$ & & & $\begin{array}{c}1.400 \\
(2.695)\end{array}$ & & & & \\
\hline Angry & & & & $\begin{array}{l}-1.287 \\
(4.443)\end{array}$ & & & \\
\hline Surprised & & & & & $\begin{array}{l}-5.504 \\
(4.569)\end{array}$ & & \\
\hline Fearful & & & & & & $\begin{array}{c}3.273 \\
(4.257)\end{array}$ & \\
\hline Disgusted & & & & & & & $\begin{array}{c}-7.186 \\
(10.979)\end{array}$ \\
\hline Rating & $\begin{array}{c}-22.156^{* * *} \\
(2.540)\end{array}$ & $\begin{array}{c}-22.156^{* * *} \\
(2.536)\end{array}$ & $\begin{array}{c}-22.231^{* * *} \\
(2.540)\end{array}$ & $\begin{array}{c}-22.232 * * * \\
(2.540)\end{array}$ & $\begin{array}{c}-22.239 * * * \\
(2.539)\end{array}$ & $\begin{array}{c}-22.233^{* * *} \\
(2.539)\end{array}$ & $\begin{array}{c}-22.231 * * * \\
(2.540)\end{array}$ \\
\hline SuperHost & $\begin{array}{c}-2.475 \\
(10.032)\end{array}$ & $\begin{array}{c}-2.203 \\
(10.043)\end{array}$ & $\begin{array}{c}-2.105 \\
(10.059)\end{array}$ & $\begin{array}{c}-2.148 \\
(10.057)\end{array}$ & $\begin{array}{c}-2.220 \\
(10.063)\end{array}$ & $\begin{array}{c}-2.130 \\
(10.059)\end{array}$ & $\begin{array}{c}-2.142 \\
(10.059)\end{array}$ \\
\hline Verified & $\begin{array}{c}-5.904 * * * \\
(1.936)\end{array}$ & $\begin{array}{c}-5.992 * * * \\
(1.937)\end{array}$ & $\begin{array}{c}-5.889 * * * \\
(1.940)\end{array}$ & $\begin{array}{c}-5.867 * * * \\
(1.939)\end{array}$ & $\begin{array}{c}-5.856^{* * *} \\
(1.939)\end{array}$ & $\begin{array}{c}-5.877 * * * \\
(1.939)\end{array}$ & $\begin{array}{c}-5.863 * * * \\
(1.939)\end{array}$ \\
\hline Provided & $\begin{array}{c}2.757 * * * \\
(0.951)\end{array}$ & $\begin{array}{c}2.811 * * * \\
(0.953)\end{array}$ & $\begin{array}{c}2.742 * * * \\
(0.953)\end{array}$ & $\begin{array}{c}2.731 * * * \\
(0.952)\end{array}$ & $\begin{array}{c}2.723 * * * \\
(0.952)\end{array}$ & $\begin{array}{c}2.744 * * * \\
(0.951)\end{array}$ & $\begin{array}{c}2.734 * * * \\
(0.952)\end{array}$ \\
\hline RegDate & $\begin{array}{c}2.461 * * * \\
(0.694)\end{array}$ & $\begin{array}{c}2.471 * * * \\
(0.696)\end{array}$ & $\begin{array}{c}2.627 * * * \\
(0.693)\end{array}$ & $\begin{array}{c}2.630 * * * \\
(0.694)\end{array}$ & $\begin{array}{c}2.628 * * * \\
(0.693)\end{array}$ & $\begin{array}{c}2.623 * * * \\
(0.693)\end{array}$ & $\begin{array}{c}2.624 * * * \\
(0.693)\end{array}$ \\
\hline Constant & $\begin{array}{c}161.799 * * * \\
(13.045)\end{array}$ & $\begin{array}{c}165.544 * * * \\
(13.063)\end{array}$ & $\begin{array}{c}163.348^{* * *} \\
(13.009)\end{array}$ & $\begin{array}{c}163.539 * * * \\
(13.033)\end{array}$ & $\begin{array}{c}163.720 * * * \\
(13.039)\end{array}$ & $\begin{array}{c}163.331 * * * \\
(13.010)\end{array}$ & $\begin{array}{c}163.504 * * * \\
(13.029)\end{array}$ \\
\hline House FE & YES & YES & YES & YES & YES & YES & YES \\
\hline Month FE & YES & YES & YES & YES & YES & YES & YES \\
\hline Obs. & 15,940 & 15,940 & 15,940 & 15,940 & 15,940 & 15,940 & 15,940 \\
\hline Prob $>F$ & 0.000 & 0.000 & 0.000 & 0.000 & 0.000 & 0.000 & 0.000 \\
\hline R-squared & 0.510 & 0.510 & 0.509 & 0.509 & 0.509 & 0.509 & 0.509 \\
\hline
\end{tabular}

Robust standard errors in parentheses

$$
\text { *** } \mathrm{p}<0.01,{ }^{* *} \mathrm{p}<0.05,{ }^{*} \mathrm{p}<0.1
$$

